\title{
EDITORIAL
}

\section{CONTRIBUTION OF VACCINATIONS TOWARDS REDUCING MORBIDITY AND MORTALITY AMONG CHILDREN IN DEVELOPING COUNTRIES}

The association between infectious diseases in children and adverse life outcome is well documented(1$3)$. While improved living conditions and better health care have reduced the devastating effects of childhood infections in industrialized countries, the same cannot be said of the developing countries(4). Common infections like tuberculosis, polio, whooping cough, tetanus, malaria, measles and diphtheria still result in high incidence of morbidity and mortality in the developing countries(1). The emergence of human immune deficiency virus infection (HIV/AIDS) has only added to the already complicated scenario(5). General poverty remains a common denominator in all these considerations. Repeated infections of children who have borderline nutritional status, especially in the developing countries, rapidly tip them into frank nutritional deficiencies which may be of micronutrient type (like Vitamin A and iron deficiency anaemia) or severe gross types (like kwashiorkor or marasmus) leading to poor growth or death. This is frequently seen with the outbreaks of measles infections $(1,3,6,7)$.

Relatively safe vaccines against most of these childhood infections: tuberculosis, polio, measles, whooping cough, tetatus and diptheria have been available and in use for nearly four decades(8). The procurement and delivery of the vaccines to the target population remained a great challenge to the developing countries before the mid 1970s until the World Health Organization initiative on Expanded Programme on Immunization (EPI) was started in 1974 and reviewed to focus on improved coverage in $1977(8,9)$. Since then, the various country EPI programmes have registered improving immunization coverage of children with reducing incidence of morbidity and mortality from the targeted infections $(4,5,8)$.

Immunizing children may also confer them with some non-specific protective effects which further reduce their morbidity and mortality. This has been demonstrated particularly with measles vaccination where reduction in child mortality from all causes other than measles of at least $30 \%$ has been reported(10-12).

Immunization programmes have been used to deliver other disease control measures in children. For example, the EPI programme in Tanzania was used to significantly reduce the rate of clinical malaria and severe anaemia in children by providing them with iron and intermittent sulphadoxine-pyrimethamine treatment during immunization(13). National immunization days (NID) which provide enhanced vaccination coverage of children have also been effectively used to provide micronutrient supplementation like Vitamin A. This was well demonstrated during the NID in Kenya in June 2002 when a national coverage for measles vaccination of $97.9 \%$ and vitamin A supplementation of $91.4 \%$ were achieved(14).

The emergence of safe and effective newer vaccines is providing a possibility of further improvement of child survival through immunization. The recombinant hepatitis $B$ vaccine, conjugated $H$. Influenzae type $b$ vaccines and the pneumococcal conjugated vaccines are already having positive impact in childhood morbidity and mortality $(4,15,16)$. On the whole, immunizing children has been quite safe and the few isolated negative effects have been far outweighed by the beneficial results $(17,18)$.

In conclusion, immunization has confirmed to improve the morbidity and mortality outcomes among children in developing countries through reduction of the incidence of specific infectious diseases, non specific reduction of infections, provision of avenue for delivering other nutritional measures and eventual overall improvement in nutrition, growth and development.

A. Wasunna, MBChB, MMed, Fell Neonat Med(Lon), Associate Professor, Department of Paediatrics and Child Health, College of Health Sciences, University of Nairobi, P.O. Box 19676, Nairobi, Kenya

\section{REFERENCES}

1. Jeena, P.M. and Coovadia, H.M. In: Child Health for All: A manual for Southern Africa. Ed: Klibel, M.A. and Wagstaff, L.A. 3rd Edition, Oxford University Press, Southern Africa. 2001; 200-221.

2. World Health Organisation. The World Health Report 1997: Conquering suffering, enriching humanity WHO, Geneva 1977.

3. Bkuskaram, P. Measles and Malnutrition. Indian J. Med. Res. 1995; 102: 125-199.

4. Bonanni, P. Demographio impact of vaccination: a review Vaccine. 1999; 3(Suppl): 5120-5125.

5. Hussey, G.D. In: Child Health for All: A manual for Southern Africa. Ed. Klibel, M.A. and Wagstaff, L.A. 3rd Edition, Oxford University Press, Southern Africa. 2001; 344-357.

6. Welch, K., Mock, N., Sorensen, B. and Netrebenko, O. Health and nutrition in children under 2 years of age in three areas of the Russian Federation. Bull. World Health Organ. 1996; 74: 605-612.

7. South African Vitamin A. Consultative Group. Anthropometric, Vitamin A, iron and immunization status in Children aged 6 - 71 months in South Africa, 1994. S. Afr. Med. J. 1996; 86: 354-357.

8. Editorial. Non-specific effects of vaccines in developing countries. Brit. Med. J. 2000; 321: 1423-1424.

9. WHO Health Magazine: Geneva Jan-Feb 1987.

10. Kabir and Kevany, J. Non-specific effects of routine vaccines on child mortality: a case-control study. Paediat. Peri. Epidem. 2001; 15: 417.

11. Aaby, P., Samb, B., Simondom, F. et al. Non-Specific beneficial effect of measles immunization: analysis of 
mortality studies from developing countries. Brit. Med. J. 1995; 311: 491-485.

12. Kristensen, I., Aaby, P. and Jensen, H. Routine Vaccinations and Child Survival follow up study in Guinea-Bissau, West Africa. Brit. Med. J. 2000; 321: 435-444.

13. Schellenberg, D., Mendez, C., Kahigwa, E. et al. Intermittent treatment for malaria and anaemia at time of routine vaccination in Tanzania Infants: a randomized placebocontrolled trial. Lancet. 2001; 357(9267): 1471-1477.

14. Ministry of Health (Kenya) Kenya Expanded Programme on Immunization Summary of Measles, OPV, Vit. A and TT SIAs. Results 17th to 23rd June 2002.

15. Goldfarb, J., Mendedorp, S.V., Garcia, H. et al. Comparison study of the immunogenials and safety of 5 and $10 \mu \mathrm{g}$ dosages of a recombinant hepatitis B vaccine in healthy infants. Paediatr. Infect. Dis. J. 1996; 15: 764-767.

16. Whitney, C.G and Pickering, L.K. The potential of pneumococcal conjugate vaccines for children. Paediatr. Infect. Dis. J. 2002; 10: 961-970.

17. Gust, I.D. The Pros and Cons of immunization-paper two: the importance of immunization. Health Care Anal. 1995; 2: $107-111$.

18. Gruber, C., Nilsson, L. and Bjorkesten, B. Do early childhood immunization influence the development of atopy and do they cause allergic reactions? Paediatr. Allergy Immunol. 2001; 12: 296-311.

\section{Do you need up-to-date peer reviewed medical literature?}

Kenya Medical Association, in collaboration with GlaxoSmithKline, is pleased to introduce

\section{KMA/GSK RESOURCE CENTRE}

A new state-of-the-art facility for frontline health workers, researchers and policy makers in Kenya to acess:

\section{CURRENT CRITICAL MEDICAL AND PUBLIC HEALTH INFORMATION DATABASES}

Relevant and reliable abstracts from leading medical journals available at the following affordable rates:

Literature Search (CD-ROM)

Printing
-Ksh. 50 per search

-Ksh. 10 per page

\section{ACCESS TO INFORMATION YOU CAN USE}

Address: KENYA MEDICAL ASSOCIATION

Chyulu Road, Upper Hill

P.O Box 41632, Code 00100, GPO, NAIROBI

E-mail: eamj@wananchi.com

Phone: 2712010

Fax: $\quad 2724617$ 